\title{
A Community Program for the Prevention Of Rheumatic Fever Recurrence
}

By MARY ALICE SMITH, M.D.

A PUBLIC HEALTH program to demonstrate techniques of community action in heart disease control began operation in Newton, Mass., in 1948. It was sponsored jointly by the Public Health Service of the Federal Security Agency, the Massachusetts Department of Public Health, and the Newton Health Department. The local medical profession was active in support of the project, and continuing leadership was given by a cardiac program committee composed of six physicians from the staff of the Newton-Wellesley Hospital. The progress of the Newton Heart Demonstration Program, as it was named, has been reported periodically (1-4). This paper is an interim accounting of rheumatic fever activities in the Newton demonstration.

Five general areas of activity were delineated at the beginning of the demonstration program in 1948: physician education, voluntary morbidity reporting, community organization, nutrition services, and rehabilitation. Subcommittees were organized for each of these areas. As experience was gained and the extent of the problem seen more clearly, some plans were modified. Morbidity reporting was abandoned. community organization was turned over to the Newton Community Council, and interest was directed to two or three new fields. One of

Dr. Smith, formerly medical officer-in-charge of the Newton (Mass.) Heart Demonstration Program, Division of Chronic Disease and Tuberculosis, Public Health Service, is now resident physician at Mount Auburn Hospital, Cambridge, Mass. these, and a major heart disease problem in Newton, was rheumatic fever.

In 1949, the most recent year for which data are available, rheumatic fever and its sequelae were the leading causes of death from disease in the 10- to 14-year-old age group; in the group between 15 and 24 it was third, being exceeded onily by tuberculosis and malignant neoplasms. The amount of chronic disability caused by rheumatic fever is also considerable. Recurrent attacks of rheumatic fever are common, particularly during the first few years following original onset, and each attack damages the heart more severely.

Rheumatic fever attacks are nearly always preceded by hemolytic streptococcal infections. The rheumatic child possesses a peculiar vulnerability and tissue reactivity to certain streptococcal infections (5). Most workers in the field now agree that the beta hemolytic streptococcus, Lancefield type $A$, precipitates the acute attack of rheumatic fever, even though the mechanism is as yet not fully understood $(6)$. Children in families in which both parents have had rheumatic fever are much more likely to develop the disease than are children of parents with no such history. Due to the influences of the genetic factor and close association, siblings of rheumatic children are especially susceptible (5).

Early treatment of streptococcal infections with penicillin prevents rheumatic fever. In an Air Force study of some 2,300 persons, immediate and thorough treatment of streptococcal infections with penicillin effected a 91 -percent reduction in the attack rate of rheumatic fever (y). The daily use of penicillin also has been 
advocated to protect rheumatic fever patients against recurrent attacks. Other members of their families, too, should be treated when they have streptococcal sore throats. Massell and his colleagues at the House of the Good Samaritan in Boston developed drug schedules in 1948 for the protection of rheumatic fever patients against recurrences $(8)$.

\section{The Newton Program}

On the basis of these and other clinical trials, the control of rheumatic fever in Newton seemed possible through application of existing knowledge even though it was incomplete. Previous reports have described in greater detail the following major steps in the development of the rheumatic fever control program in Newton, a Boston suburb with a population of 85,000 :

1. At a meeting held in December 1949, the cardiac program committee authorized a telephone survey of physicians to determine the extent of preventive measures then being taken. From this survey, it was learned that virtually no efforts were being made to prevent recurrence of rheumatic fever.

2. As a result of these findings, a rheumatic fever subcommittee was set up to continue the program.

3. Massell's oral penicillin prophylactic schedules (4) were obtained by the subcommittee and introduced at one of the regular teaching sessions sponsored by the subcommittee on physician education.

4. A plan was adopted for penicillin to be dispensed by the health department upon the physician's prescription, at low cost, or free to those unable to pay.

5. So that physicians might acquaint rheumatic fever patients with the preventive care desirable for them, it was planned that the director of public health would write to rheumatic patients listed in his handicapped children's file, requesting them to visit their physicians for advice about prophylaxis.

6. In order to find families with children having a history of rheumatic fever, the cooperation of the public and parochial schools was obtained. A survey form distributed to 14,000 children requested their parents to indicate any knowledge of rheumatic fever in the family and, for verification of diagnosis, to include the name of the family doctor.

7. It was also decided that a study of the prophylaxis program should be made to evaluate the effectiveness of efforts to place persons susceptible to rheumatic fever under their doctor's care, as well as the effectiveness of the penicillin dosage schedule itself in preventing recurrences of rheumatic fever.

During February and March 1950, these plans: were put into effect: The availability of lowcost penicillin was announced; letters were sent to the parents of school children in an attempt to procure additional rheumatic fever histories; and families known to include rheumatic fever patients received letters asking them to visit their physicians for appropriate instruction. As new rheumatic fever families were found, they, too, were directed to their doctors for prophylactic care. During the early months of the program, also, personal visits were made to physicians known to have rheumatic fever patients in their practice. To determine the approximate prevalence of streptococcal infection in the community, free throat cultures of patients with suspected streptococcal infections were made by the Newton-Wellesley Hospital (9).

In the fall of 1950, another announcement was made concerning the availability of low-cost penicillin and use of the prophylactic schedules. As a diagnostic aid, the local physicians then received a copy of a definitive article by Dr. T. Duckett Jones, outlining criteria for the diagnosis of rheumatic fever (10).

\section{The Study Group}

In December 1949, just before the program was instituted, only 16 percent of the known rheumatic fever patients were receiving any kind of protection against recurrence of their rheumatic fever. After record searching, physician interviews and analysis of the family history questionnaires, it was believed that, as of January 18, 1952, all patients in need of prophylactic care were known to the health department. On that date there were 74 such patients in the community of whom 55 were known to have had their initial attack since the 
beginning of 1945 (table 1). All of these 74 persons had been offered and were then receiving some type of prophylactic care. In terms of the type of preventive measures advised, there were three groups of patients.

The schedule (4) recommended to 52 persons consisted of continuous daily prophylactic therapy for 5 years after the date of their last attack. Forty-four of these persons had had initial attacks since the beginning of 1945. There were 15 patients whose physicians were relying on the immediate treatment of streptococcal infections to protect them against rheumatic fever recurrence, only 5 of whom were known to have had their first attack since 1945. The seven patients receiving sulfonamides had been taking them before the program began-all but one of these were under the care of physicians practicing outside Newton (table 1).

All but 1 of the 74 patients were between 5 and 21 years of age. Most of those who were known to have had signs or symptoms of carditis were in the "regular" penicillin clas-

Table 1. Rheumatic fever patienis in prophylaxis sfudy, Newton, Mass., by type of therapy and time of first attack, as of January 18, 1952

\begin{tabular}{|c|c|c|c|c|c|}
\hline \multirow[b]{2}{*}{$\begin{array}{l}\text { Time of first } \\
\text { attack }\end{array}$} & \multirow[b]{2}{*}{ Total } & \multicolumn{2}{|c|}{$\begin{array}{l}\text { Number } \\
\text { receiving } \\
\text { penicillin }\end{array}$} & \multirow{2}{*}{ 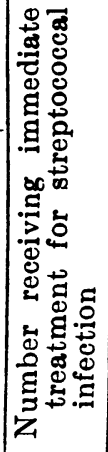 } & \multirow{2}{*}{ 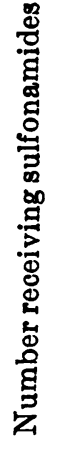 } \\
\hline & & 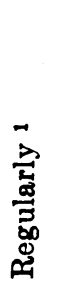 & 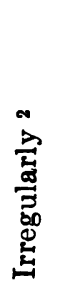 & & \\
\hline Total . . . . . & 74 & 28 & 24 & 15 & 7 \\
\hline $\begin{array}{r}\text { Prior to: } \\
1945 \ldots \\
1945 \ldots \\
1946 \\
1947 \\
1948 \\
1949 \\
1950 \ldots \\
1951 \ldots \\
\text { Not known }\end{array}$ & $\begin{array}{r}7 \\
7 \\
8 \\
10 \\
6 \\
10 \\
10 \\
4 \\
12\end{array}$ & $\begin{array}{l}2 \\
3 \\
4 \\
6 \\
1 \\
2 \\
6 \\
3 \\
1\end{array}$ & $\begin{array}{l}1 \\
1 \\
1 \\
2 \\
4 \\
8 \\
2 \\
1 \\
4\end{array}$ & $\begin{array}{l}3 \\
1 \\
\mathbf{2} \\
\mathbf{0} \\
\mathbf{1} \\
\mathbf{0} \\
\mathbf{1} \\
\mathbf{0} \\
\mathbf{3}\end{array}$ & $\begin{array}{l}1 \\
2 \\
1 \\
2 \\
0 \\
0 \\
1 \\
0 \\
0\end{array}$ \\
\hline
\end{tabular}

1 Returned within given time limits for refill.

2 Failed to return within given time limits for refill

31 over 21 years of age.
Table 2. Payment sfatus of rheumatic fever patients receiving penicillin prophylaxis, as of January 18, 1952

\begin{tabular}{|c|c|c|c|}
\hline \multirow{2}{*}{ Type of prophylaxis } & \multicolumn{3}{|c|}{ Number of patients } \\
\hline & Total & Paying & $\begin{array}{l}\text { Non- } \\
\text { paying }\end{array}$ \\
\hline Total. & 67 & 36 & 31 \\
\hline Penicillin regularly $\ldots . . .$. & 28 & 13 & 15 \\
\hline Penicillin irregularly & 24 & 10 & 14 \\
\hline $\begin{array}{l}\text { Immediate treatment for } \\
\text { streptococcal infections. }\end{array}$ & 15 & 13 & 2 \\
\hline
\end{tabular}

sification. Involved in the care of these rheumatic fever patients were 37 physicians, 26 practicing in Newton and 11 outside the city, and 3 clinics, of which 2 were attached to the local hospital.

The patients who received penicillin are grouped in table 2 according to their payment status. Since the price of penicillin for 1 year was only about $\$ 60$ per patient under the lowcost plan, many parents were able to pay this sum to prevent recurrences of the illness. However, when families could not afford the low-cost penicillin, their physicians could recommend that it be furnished without charge.

\section{"Regular" vs. "Irregular"}

More than half of the 52 persons who were taking penicillin received it regularly, returning to the health department about once a month for 33 days' supply. There were 24, however, who were somewhat irregular in following the regimen and did not obtain sufficient penicillin to take the prescribed dosages. Some effort was made to discover why these 24 were irregular in obtaining penicillin refills. Since there were about equal numbers in the groups paying and not paying within the classes getting "regular" and "irregular" penicillin refills, it is likely that some factors other than cost influenced the "irregular" group to neglect to obtain their monthly supplies. Of the 28 patients returning regularly, 17 were given prophylaxis within the first 3 months 
of 1950 , coincident with the major education effort. The remaining 11 were added to the series at a rate of about 1 each month thereafter.

Interviews with the physicians brought out the fact that, in more than half the instances where patients were replenishing supplies only irregularly, the physicians had been unaware of the irregularities until these were brought to their attention. The same physicians were asked for their reaction to the suggestion that the health department should send out reminder cards to patients when their supply should have been consumed. Only about half the opinions favored this measure, and the suggestion was not pursued.

Some physicians were able to keep all their patients in the "regular" penicillin category throughout the period of this study. Others were unsuccessful in teaching all of their patients the advantages of the regular use of penicillin.

Three physicians had patients in all three of the treatment categories-prophylactic penicillin, sulfonamides, immediate treatment for streptococcal infections.

Of the 28 patients in the "regular" penicillin group, their physicians reported that only one had had a streptococcal infection while receiving penicillin-a patient with scarlet fever in whom repeated throat cultures revealed no beta hemolytic streptococci. At least 11 other nonstreptococcal infections, however, did occur within this same group. No penicillin reactions were reported by physicians.

There were no recurrences of rheumatic fever among the 74 patients through January 18, 1952.

The program will be continued by a routine procedure in which, on finding children with rheumatic fever (as, for example, through a school physical examination), the health de- partment will send the child's physician an announcement of the availability of penicillin and $a$ request that he return a card noting prophylactic measures being taken and permissible physical education activities at school.

\section{REFERENCES}

(1) Kattwinkel, Egon E., Getting, Vlado A., Morris, Ernest M., Lombard, Herbert M., and Robbins, Lewis C.: A public health heart programFirst report. New Eng. J. Med. 241: $446-449$ (1949).

(2) Kattwinkel, Egon E., Morris, Ernest M., and Robbins, Lewis C.: Progress report of the Newton heart demonstration program. New Eng. J. Med. 243: 115 (1950).

(ङ) Kattwinkel, Egon E., Getting, Vlado A., Morris, Ernest M., and Zukel, William J.: A community heart program-Report of three years' experience. New Eng. J. Med. 245: 595-598 (1951).

(4) Smith, Mary Alice, Fried, Anton R., Morris, Ernest M., Robbins, Lewis C., and Zukel, William J.: Rheumatic fever prophylaxis-A community program through the private physician. J. A. M. A. 149: 636-639 (1952).

(5) Wilson, May G.: Rheumatic fever. New York, The Commonwealth Fund, 1940.

(6) Swift, Homer F.: The etiology of rheumatic fever. Ann. Int. Med. 31: 715-738 (1949).

(y) Wannamaker, L. W., Rammelkamp, C. H., Jr., Denny, F. W., Brink, W. R., Houser, H. B., Hahn, E. O., and Dingle, J. H.: Prophylaxis of acute rheumatic fever by treatment of the preceding streptococcal infection with various amounts of depot penicillin. Am. J. Med. 10: 673-695 (1951).

(8) Massell, B. F., Dow, J. W., and Jones, T. Duckett: Orally administered penicillin in patients with rheumatic fever. J. A. M. A. 138: 1030-1035 (1948).

(9) Smith, Mary Alice, Skinner, D., and Erickson, L. : Prophylactic effect of penicillin tablets on throat flora. Am. J. Clin. Path. 22: 948-951 (1952).

(10) Jones, T. Duckett: The diagnosis of rheumatic fever. J. A. M. A. 126: 481-484 (1944). 